\title{
FAKTOR FAKTOR YANG MEMPENGARUHI PENDAPATAN UMKM PANDAN WANGI DI DESA TUMBAKBAYUH KECAMATAN MENGWI KABUPATEN BADUNG
}

\author{
I Made Hary Kusmawan ${ }^{1}$ \\ Ni Putu Juniari²
}

\author{
Fakultas Ekonomi Dan Bisnis Universitas Tabanan, Bali, Indonesia ${ }^{1,2}$ \\ email: harykusmawan@gmail.com
}

\begin{abstract}
Micro, Small and Medium Enterprises (MSMEs) are an important part of a country's economy. This important role has encouraged many countries including Indonesia to continue to strive to develop MSMEs. The objectives of this study were (1) To determine whether the length of business had a partial effect on the income of Pandan Wangi MSMEs in Tumbakbayuh Village, Mengwi District, Badung Regency, (2) To determine whether the number of workers had a partial effect on the income of Pandan Wangi MSMEs in the Village. Tumbakbayuh, Mengwi District, Badung Regency, and (3) To find out whether the length of effort and the number of workers have a simultaneous effect on the income of Pandan Wangi MSMEs in Tumbakbayuh Village, Mengwi District, Badung Regency. The samples in this study were all Pandan Wangi SMEs in Tumbakbayuh Village, Mengwi District, Badung Regency using the saturated sample method, with the analysis technique using multiple linear regression. Based on the results of the analysis of the length of business, it has a partial effect on the income of SMEs Pandan Wangi in Tumbakbayuh Village, Mengwi District, Badung Regency, because the t-count value is greater than the t-table value or the -t-count value is smaller than the -t table value, the number of workers has a partial effect. on the income of Pandan Wangi MSMEs in Tumbakbayuh Village, Mengwi District, Badung Regency, because the tcount value is greater than the table value or the -t count value is smaller than the -t table value, the length of business and the number of workers have a simultaneous effect on the income of MSMEs Pandan Wangi in Tumbakbayuh Village, Mengwi District, Badung Regency, because the calculated $F$ value is greater than the F table value.
\end{abstract}

Keywords: $\quad$ old business, labor and UMKM income

\section{PENDAHULUAN}

Pembangunan ekonomi suatu daerah atau suatu negara pada dasarnya merupakan interaksi dari berbagai kelompok variabel, antara lain sumber daya manusia, sumber daya alam, modal, teknologi dan lainlain. Indonesia sebagai sebuah negara dimana pembangunan nasionalnya pada hakikatnya memiliki salah satu tujuan yaitu memajukan kesejahteraan umum. Pembangunan adalah suatu proses atau kegiatan yang berjalan secara terus-menerus dari waktu ke waktu untuk mewujudkan suatu tujuan tertentu, yang pada dasarnya tujuan tersebut adalah agar tercapainya suatu kemakmuran dan keadilan. Saat ini setiap negara berkembang harus melakukan proses perubahan ke arah modernisasi dengan cara 
melaksanakan pembangunan di segala bidang. Usaha Mikro Kecil Menengah (UMKM) di daerah Kecamatan Mengwi telah banyak menunjang pembangunan dalam sektor Usaha Mikro Kecil Menengah (UMKM) dilaksanakan yang bertujuan untuk meningkatkan taraf hidup, meningkatkan perekonomian dan pendapatan masyarakat serta meningkatkan kualitas SDM, yang semuanya itu adalah untuk peningkatan kesejahteraan seluruh lapisan masyarakat di Kabupaten Badung, Kecamatan Mengwi, khususnya di Desa Tumbakbayuh.

\section{Rumusan Masalah}

Berdasarkan latar belakang masalah di atas maka dapat dirumuskan beberapa masalah sebagai berikut:

1. Bagaimana lama usaha berpengaruh secara parsial terhadap pendapatan UMKM Pandan Wangi di Desa Tumbakbayuh, Kecamatan Mengwi, Kabupaten Badung?

2. Bagaimana jumlah tenaga kerja berpengaruh secara parsial terhadap pendapatan UMKM Pandan Wangi di Desa Tumbakbayuh, Kecamatan Mengwi, Kabupaten Badung?

3. Bagaimana lama usaha dan jumlah tenaga kerja berpengaruh secara simultan terhadap pendapatan UMKM Pandan Wangi di Desa Tumbakbayuh, Kecamatan Mengwi, Kabupaten Badung?

\section{Tujuan Penelitian}

Berdasarkan rumusan masalah di atas, maka tujuan dalam penelitian ini adalah untuk:

1. Mengetahui pengaruh lama usaha secara parsial terhadap pendapatan UMKM Pandan Wangi di Desa
Tumbakbayuh, Kecamatan Mengwi, Kabupaten Badung.

2. Mengetahui pengaruh jumlah tenaga kerja secara parsial terhadap pendapatan UMKM Pandan Wangi di Desa Tumbakbayuh, Kecamatan Mengwi, Kabupaten Badung.

3. Mengetahui pengaruh lama usaha dan jumlah tenaga kerja secara simultan terhadap pendapatan UMKM Pandan Wangi di Desa Tumbakbayuh, Kecamatan Mengwi, Kabupaten Badung.

\section{METODE PENELITIAN Hipotesis}

Berdasarkan pokok permasalahan dan penelitian sebelumnya yang dikemukan di atas maka hipotesis yang diajukan dalam penelitian ini adalah sebagai berikut:

1. Lama usaha berpengaruh positif dan signifikan secara parsial terhadap pendapatan UMKM pandan wangi di Desa Tumbakbayuh, Kecamatan Mengwi, Kabupaten Badung.

2. Jumlah tenaga kerja berpengaruh positif dan signifikan secara parsial terhadap pendapatan UMKM pandan wangi di Desa Tumbakbayuh, Kecamatan Mengwi, Kabupaten Badung.

3. Lama usaha dan jumlah tenaga kerja berpengaruh positif dan signifikan secara simultan terhadap pendapatan UMKM pandan wangi di Desa Tumbakbayuh, Kecamatan Mengwi, Kabupaten Badung.

\section{Lokasi Penelitian}

Penelitian ini dilakukan di

Desa Tumbakbayuh, Kecamatan Mengwi, Kabupaten Badung dikarenakan pendapatan UMKM Pandan Wangi di Desa Tumbakbayuh, 
Kecamatan Mengwi, Kabupaten Badung musti harus ditinjau lagi, dan objek dalam penelitian ini adalah lama usaha, jumlah tenaga kerja dan pendapatan UMKM Pandan Wangi di Desa Tumbakbayuh, Kecamatan Mengwi, Kabupaten Badung.

\section{Identifikasi Variabel}

Indentifikasi variabel untuk mengetahui pengaruh lama usaha dan jumlah tenaga kerja terhadap pendapatan UMKM Pandan Wangidi Desa Tumbakbayuh, Kecamatan Mengwi, Kabupaten Badung menggunakan dua variabel bebas dan satu variabel terikat. Variabel terikat (Y) adalah variabel yang dipengaruhi oleh variabel bebas, dalam hal ini adalah pendapatan UMKM Pandan Wangi di Desa Tumbakbayuh, Kecamatan Mengwi, Kabupaten Badung. Variabel bebas adalah variabel yang tidak tergantung dan tidak dipengaruhi oleh variabel lain, namun mempengaruhi variabel terikat. Dalam penelitian ini sebagai variabel bebas $\mathrm{X}_{1}$ adalah lama usaha dan variabel bebas $\mathrm{X}_{2}$ adalah jumlah tenaga kerja.

\section{Teknik dan Analisis Data}

1. Analisis Regresi Linier Berganda Analisis ini digunakan untuk mengetahui bagaimana pengaruh lama usaha dan jumlah tenaga kerja terhadap pendapatan UMKM Pandan Wangi Di Desa Tumbak Bayuh Kecamatan Mengwi Kabupaten Badung. Perhitungan dapat dicari dengan rumus (Gujarati : 1995)

$\mathrm{Y}=\mathrm{bo}+\mathrm{b} 1 \mathrm{X} 1+\mathrm{b} 2 \mathrm{X} 2+\mathrm{ei}$

2. Koefisien determinasi berganda Koefisien determinasi berganda dilambangkan dengan $\mathrm{R}^{2}$ yang merupakan ukuran kesesuaian garis regresi linear berganda terhadap suatu data. Nilai koefisien determinasi berganda terletak antara 0 dan $1\left(0 \leq \mathrm{R}^{2} \leq 1\right)$.

\section{HASIL DAN PEMBAHASAN}

Kecamatan Mengwi adalah salah satu dari enam Kecamatan di Kabupaten Badung yang keadaan geografisnya terbentang menyerupai sebilah keris dari wilayah Selatan yang berada di Desa Cemagi sampai dengan ujung Utara di Desa Kuwum, dengan luas 82,00 $\mathrm{Km} 2$, terdiri dari 5 Kelurahan dan 15 Desa dan 187 banjar Dinas/Lingkungan dan 38 Desa Adat, 211 Banjar adat , yaitu Kelurahan Kapal, Abianbase, Sading, Lukluk dan Sempidi sedangkan Desa Cemagi, Munggu, Pereranan, Tumbakbayuh, Buduk, Kekeran, Mengwitani, Mengwi, Gulingan, Penarungan, Baha, Werdi Bhuana, Sobangan, Sembung dan Desa Kuwum.

\section{Deskripsi Hasil Penelitian}

\section{Analisis Regresi Linier Berganda}

Model analisis yang digunakan dalam penelitian ini adalah regresi linear berganda, yaitu untuk mengetahui pengaruh lama usaha dan jumlah tenaga kerja terhadap pendapatan UMKM Pandan Wangi di Desa Tumbakbayuh, Kecamatan Mengwi, Kabupaten Badung. Pembuktian hipotesis digunakan uji statistik yaitu uji t dan uji F. Untuk mengolah data dari penelitian ini, analisis data dilakukan dengan mengunakan software SPSS (Statistical Product and Service Solution). Data hasil olahan SPSS atau hasil perhitungan SPSS dapat dilihat pada tabel berikut: 


\section{Tabel 1}

Rangkuman Hasil Perhitungan Analisis SPSS

\begin{tabular}{|c|c|c|c|c|c|c|c|}
\hline & & B & Std. Error & $\mathrm{T}$ & Sig. & Tolerance & VIF \\
\hline (Costant) & & 1521058.638 & 178758.445 & 8.509 & 0.000 & & \\
\hline Lama Us & $\mathrm{a}\left(\mathrm{X}_{1}\right)$ & 421128.862 & 55547.975 & 7.581 & 0.000 & 0.468 & 2.138 \\
\hline Tenaga $\mathrm{K}$ & rja $\left(\mathrm{X}_{2}\right)$ & 2060048.461 & 237895.586 & 8.659 & 0.000 & 0.468 & 2.138 \\
\hline $\mathrm{R}$ & \multicolumn{2}{|c|}{ R Square Change $\left(\mathrm{R}^{2}\right)$} & F Change & \multicolumn{2}{|c|}{ Sig. F Change } & \multicolumn{2}{|c|}{$\begin{array}{l}\text { Durbin- } \\
\text { Watson }\end{array}$} \\
\hline 0.910 & & 0.829 & 65.411 & & 0.000 & \multicolumn{2}{|c|}{1.650} \\
\hline
\end{tabular}

Sumber: Hasil Pengolahan SPSS (2020)

$\hat{\mathbf{Y}}=1521058.638+421128.862$

$\mathrm{X} 1+2060048.461 \mathrm{X} 2$

1. Nilai a (kostanta) sebesar 1521058.638 memiliki arti bahwa rata-rata pendapatan UMKM Pandan Wangi di Desa Tumbakbayuh, Kecamatan Mengwi, Kabupaten Badung adalah sebanyak 1.521.058,638 rupiah, dengan asumsi variabel lama usaha $\left(\mathrm{X}_{1}\right)$ dan jumlah tenaga kerja $\left(\mathrm{X}_{2}\right)$ dianggap konstan atau tetap.

2. Nilai $b_{1}$ (koefisien regresi $X_{1}$ ) sebesar 421128.862 memiliki arti bahwa peningkatan lama usaha sebanyak satu tahun akan meningkatkan pendapatan UMKM Pandan Wangi di Desa Tumbakbayuh, Kecamatan Mengwi, Kabupaten Badung ratarata sebesar 421.128,862 rupiah, dengan asumsi variabel jumlah tenaga kerja $\left(\mathrm{X}_{2}\right)$ dianggap konstan atau tetap.

3. Nilai b2 (koefisien regresi $\mathrm{X}_{2}$ ) sebesar 2060048.461 memiliki arti bahwa peningkatan jumlah tenaga kerja sebanyak satu orang akan meningkatkan pendapatan UMKM Pandan Wangi di Desa Tumbakbayuh, Kecamatan Mengwi, Kabupaten Badung ratarata sebesar 2.060.048,461 rupiah, dengan asumsi variabel lama usaha $\left(\mathrm{X}_{1}\right)$ dianggap konstan atau tetap.

\section{Koefisien determinasi berganda}

Koefisien determinasi

berganda digunakan untuk mengukur ketepatan dari model analisis yang dibuat. Nilai koefisien determinasi berganda adalah alat analisis untuk mengukur besarnya sumbangan dari variabel lama usaha $\left(\mathrm{X}_{1}\right)$ dan jumlah tenaga kerja $\left(\mathrm{X}_{2}\right)$ terhadap pendapatan UMKM Pandan Wangi di Desa Tumbakbayuh, Kecamatan Mengwi, Kabupaten Badung (Y). Berdasarkan tabel 4.6 diketahui nilai koefisien determinasi berganda yaitu $R^{2}=0.829$, ini berarti variasi naik turunya pendapatan UMKM Pandan Wangi di Desa Tumbakbayuh, Kecamatan Mengwi, Kabupaten Badung (Y) 82.9 persen dipengaruhi oleh lama usaha $\left(\mathrm{X}_{1}\right)$ dan jumlah tenaga kerja $\left(\mathrm{X}_{2}\right)$ dan sisanya sebesar 17.1 persen dipengaruhi oleh variasi variabel lain diluar model yang tidak dimasukan dalam penelitian ini.

\section{Hasil Pengujian Hipotesis}

1. Uji $t$ hipotesis pertama secara parsial $\mathrm{X}_{1}$

Berdasarkan tabel 4.6 dapat diketahui bahwa nilai t hitung $b_{1}$ sebesar 7.581 dan signifikasinya adalah sebesar 0.000 Angka-angka ini memberikan arti bahwa lama usaha $\left(\mathrm{X}_{1}\right)$ mempunyai pengaruh nyata secara parsial terhadap pendapatan UMKM Pandan Wangi di Desa Tumbakbayuh, 
Kecamatan Mengwi, Kabupaten Badung (Y), karena nilai t hitung lebih besar dari nilai $t$ tabel $(7.581$ $>2.052$ ) atau nilai -t hitung lebih kecil dari nilai -t tabel $(-7.581<-$ 2.052) dan signifikansi lebih kecil dari pada $0.05(5 \%)$ yaitu 0.000 $(0.000<0.05)$.

2. Uji t hipotesis kedua secara parsial $\mathrm{X}_{2}$

Berdasarkan tabel 4.6 dapat diketahui bahwa nilai $\mathrm{t}$ hitung sebesar 8.659 dan signifikasinya adalah sebesar 0.000 Angka-angka ini memberikan arti bahwa jumlah tenaga kerja $\left(\mathrm{X}_{2}\right)$ mempunyai pengaruh nyata secara parsial terhadap pendapatan UMKM Pandan Wangi di Desa Tumbakbayuh, Kecamatan Mengwi, Kabupaten Badung (Y), karena nilai t hitung lebih besar dari nilai t tabel $(8.659>2.052)$ atau nilai -t hitung lebih kecil dari nilai -t tabel $(-8.659<-2.052)$ dan signifikansi lebih kecil dari pada $0.05(5 \%)$ yaitu $0.000(0.000<$ $0.05)$.

3. Uji F (Pengujian secara simultan)

Diketahui bahwa nilai $\mathrm{F}$ hitung sebesar 65.411 dan signifikasinya adalah sebesar 0.000. Angkaangka ini memberikan arti bahwa lama usaha $\left(\mathrm{X}_{1}\right)$ dan jumlah tenaga kerja (X2) mempunyai pengaruh nyata secara simultan terhadap pendapatan UMKM Pandan Wangi di Desa Tumbakbayuh, Kecamatan Mengwi, Kabupaten Badung (Y), karena nilai $\mathrm{F}$ hitung lebih besar dari pada nilai $\mathrm{F}$ tabel atau (65.411>3.350) dan signifikansi lebih kecil dari pada $0.05(5 \%)$ yaitu $0.000(0.000<$ $0.05)$.

\section{SIMPULAN DAN SARAN Simpulan}

Berdasarkan olah data dan hasil analisis pengujian data secara deskriptif dan statistik, maka dapat diperoleh beberapa simpulan sebagai berikut:

1. Lama usaha berpengaruh positif dan signifikan secara parsial terhadap pendapatan UMKM Pandan Wangi di Desa Tumbakbayuh, Kecamatan Mengwi, Kabupaten Badung.

2. Jumlah tenaga kerja berpengaruh positif dan signifikan secara parsial terhadap pendapatan UMKM Pandan Wangi di Desa Tumbakbayuh, Kecamatan Mengwi, Kabupaten Badung.

3. Lama usaha dan jumlah tenaga kerja berpengaruh positif dan signifikan secara simultan terhadap pendapatan UMKM Pandan Wangi di Desa Tumbakbayuh, Kecamatan Mengwi, Kabupaten Badung.

\section{Saran}

Berdasarkan latar belakang sampai dengan simpulan diatas maka penulis mengemukakan beberapa saran, sehubungan dengan pokok penelitian ini:

1. Mengingat lama usaha berpengaruh positif dan signifikan secara parsial terhadap pendapatan UMKM Pandan Wangi di Desa Tumbakbayuh, Kecamatan Mengwi, Kabupaten Badung, maka dengan ini disarankan pemilik usaha sebaiknya menjaga kualitas UMKM Pandan Wangi yang sudah dibangun, sehingga UMKM pandan wangi tersebut terus dapat melakukan kegiatan usahanya.

2. Karena jumlah tenaga kerja perpengaruh positif dan signifikan 
secara parsial terhadap pendapatan UMKM Pandan Wangi di Desa Tumbakbayuh, Kecamatan Mengwi, Kabupaten Badung, maka disarankan pelaku usaha pandan wangi bisa menambah tenaga kerja yang dipekerjakan dan selalu memperhitungkan kreatifitas penggunaan tenaga kerja sehingga pendapatan UMKM Pandan Wangi di Desa Tumbakbayuh dapat di tingkatkan dengan memperhatikan situasi dan kondisi usahanya.

3. Variabel lama usaha dan jumlah tenaga kerja mempunyai pengaruh positif dan signifikan secara simultan terhadap pendapatan UMKM Pandan Wangi di Desa Tumbakbayuh, Kecamatan Mengwi, Kabupaten Badung maka disarankan pihak pemerintah membuat kebijakan yang tepat untuk mengembangkan UMKM Pandan Wangi yang ada dan pemerintah bisa membuat balai latihan bagi tenaga kerja yang ingin mendirikan UMKM Pandan Wangi, sehingga tenaga kerja semakin terlatih untuk mendirikan UMKM Pandan Wangi yang siap bersaing dengan usaha lainnya yang sejenis.

\section{DAFTAR PUSTAKA}

Agussalim. 2009. Masalah Kemiskinan dan Ketenaga Kerjaan di Masyarakat. Jakarta: Balai Pustaka.

Arikunto Suharsimi. 2010. Metode Penelitian. Jakarta: Erlangga.

Azrin. 2004. Usaha Kecil Menengah. Jakarta. Gramedia Pustaka Utama
Badan Pusat Statistik.2019. Kecamatan Mengwi Dalam Angka 2019. Laporan Tahunan. Badung:BPS Kabupaten Badung.

Dinas Perindustrian dan Perdagangan (Disperindag) Kabupaten Badung. 2019.

Djojohadikusumo, Sumitro. 2010. Dasar Teori Ekonomi Pertumbuhan dan Ekonomi Pembangunan . Jakarta: MasPustaka.

Imam Ghozali. 2013. Aplikasi Analisis Multivariate dengan Program IBM SPSS 19. Semarang: Badan Penerbit Universitas Diponogoro

Jhingan, M.L. 2010. Ekonomi Pembangunan dan Perencanaan. Jakarta: Rajawali Press.

Nazir, Moh. 2013. Metode Penelitian. Bogor: Ghalia Indonesia.

Payaman J. Simanjuntak. 2011. Manajemen Evaluasi Kinerja .Edisi 3. Jakarta. Fakutas UI

Poniwati, Asmie. 2010. Analisis Faktor-Faktor Yang Mempengaruhi Tingkat Pendapatan Pedagang Pasar Tradisional di Kota Yogyakarta. Yogyakarta : Universitas Gajah Mada.

Sadono. Soekirno. 2014. Ekonomi Pembangunan. Jakarta: Gramedia Pustaka Utama. 
Siagian, Sondang P., 2011. Manajemen Sumber Daya Manusia (Edisi Pertama). Jakarta: Binapura Aksara

Soetrisno. 2011. Manajemen Usaha. Jakarta: Grasindo.

Sumarsono, Sonny. 2013. Teori Kebijakan Publik Ekonomi Sumber Daya Manusia. Yogyakarta : Graha Ilmu

Sriyana, Jaka. 2010. Metode Regresi Data Panel. Yogyakarta: Penerbit Ekonisia.

Sugiyono., 2011. Metode Penelitian Kombinasi. (Cetakan Pertama). Jakarta : Alfabeta.

Suparmoko, 2009, Pengantar Ekonomi Makro. Yogyakarta: Alfa Media.

Supriyati. 2011. Metodologi Penelitian.Bandung: Labkat press

Undang-Undang No. 13 tahun 2003. Tentang Ketenagakerjaan.

Undang-Undang RI No. 32 Tahun 2004. Tentang Pemerintahan Daerah.

UU No. 20 Tahun 2008, Tentang UMKM

Wiana. I Ketut. 2009. Sembahyang Menurut Hindu.

Wirawan. Nata. 2009. Cara Mudah Memahami Statistik (Statistik Inpensia) untuk Ekonomi dan Bisnis. Denpasar: Keraras Emas. 